\title{
Gynaecological bacterial infections: the physical and psychosocial consequences and challenges of management in resource-limited settings
}

\author{
Charles O. Adiri, Uchenna I. Nwagha, Tochukwu C. Okeke, Emmanuel O. Izuka*
}

Department of Obstetrics and Gynecology, University of Nigeria, Ituku-Ozalla, Enugu, Enugu State, Nigeria

Received: 28 July 2019

Accepted: 05 September 2019

*Correspondence:

Dr. Emmanuel O. Izuka,

E-mail: izuksman@yahoo.com

Copyright: () the author(s), publisher and licensee Medip Academy. This is an open-access article distributed under the terms of the Creative Commons Attribution Non-Commercial License, which permits unrestricted non-commercial use, distribution, and reproduction in any medium, provided the original work is properly cited.

\begin{abstract}
Gynecological bacterial infections (GBIs) are prevalent in our environment and as a result pose a number of physical, social and psychological consequences. These infections are acquired through several ways. Treating GBIs is a daunting task making its control the most important strategy to alleviating its physical and psychosocial consequences. To highlight the physical, social, and psychological consequences of gynaecological bacterial infections in our resource limited setting. To highlight the hugely unresolved challenges associated with the management of gynecological bacterial infections in our resource-limited setting. Several databases (Medline, Google Scholar, Pubmed, WHO's Hinari and Wikipedia) and some selected websites were searched using the following keywords: gynecological infections, vaginal infections and discharges, vaginal flora, sexually transmitted infections, pelvic inflammatory disease, syndromic management and challenges, psychosocial consequences, alternative medicine. A total of 5470 relevant articles were obtained between 1947 and 2018. Out of these only 256 relevant articles on the topic were reviewed. However, 213 were dropped for having an incomplete submission. Forty-three (43) articles were fully accessed and referenced. The high prevalence of GBIs poses a lot of burden on the reproductive and socio-economic lives of our women. This should be matched by behavioral changes, prompt diagnosis and early treatment; facilitated by accessible and affordable health care through improved government funding.
\end{abstract}

Keywords: Gynecological infections, vaginal infections and discharges, Pelvic inflammatory disease, Psychosocial consequences, Sexually transmitted infections, Syndromic management of STIs and challenges, Vaginal flora

\section{INTRODUCTION}

The female genital tract notably the vagina is colonized by microorganisms especially bacteria. While majority of the bacteria may be harmless (lactobacilli), others have varying degrees of virulence. The proximity of the vagina to the anal canal and the urethral meatus makes it susceptible to bacteria colonization. Also, menstrual, sexual and reproductive activities make it easy for the female genital tract to be colonized by many bacterial organisms.

In normal and asymptomatic women of reproductive age, the vaginal flora includes aerobic and obligate anaerobic organisms with the latter predominating by a ratio of 10:1.1 More than two dozen bacterial species constitute the normal vaginal flora. ${ }^{1-4}$ The flora over the course of a menstrual cycle changes in population and virulence..$^{5-9}$ 
The female genital tract is endowed with mechanisms that halt these ravaging microorganisms and ensure that a harmonious relationship exists. ${ }^{10}$ The mechanisms include the presence of specialized apocrine glands whose secretions inhibit bacterial growth, mechanical barrier offered by the labia, numerical superiority of Lactobacillus species and protection by the stratified squamous non-keratinizing epithelium of the vagina.10 Other factors are the presence of cervical mucus plug, cyclical shedding of the endometrium in each menstrual cycle, the host's immunological response, as well as vaginal mucosa that produce immunoglobulins - an important aspect of the humoral immune system. ${ }^{10-12}$

In spite of all these defence mechanisms, infections do occur when any or some of the under-listed factors supervene, such as; poor personal hygiene, impaired immunity and chronic debilitating conditions, previous infections, non-use of barrier contraception and frequent douching and spermicides use, indiscriminate use of antibiotics and changes in hormone levels due to pregnancy, breastfeeding or menopause. ${ }^{13,14}$

Other risk factors include young age, black race, unprotected intercourse, loss of mucus plug at ovulation and menstruation, reduced or absence of lactobacillus species prior to puberty and at menopause. ${ }^{15-17}$ Gynecological procedures like illegal abortions, dilatation and curettage, hysterosalpingogram, insertion of intrauterine contraceptive devices and pelvic surgeries; obstetric procedures like normal deliveries, instrumental vaginal deliveries and manual removal of the placenta can all lead to infections. ${ }^{16}$

Social factors contribute to the spread of GBIs. Certain occupations like migrant men in the military, the police and drivers are also at risk. ${ }^{17}$

Economic factors are also involved in the spread of infections as evidenced by the activities of sex workers where the poor sell sex and the rich buy sex. ${ }^{18-20}$ Ignorance about the existence and risks of infections, substance abuse and moral decadence in our youths, wartime atrocities (crimes) and adverse economic situations are other causes. In Nigeria, young age, low level of education, and poverty are known risk factors. ${ }^{21}$

This narrative review aims to evaluate the physical and psychosocial consequences of gynecological bacterial infections and the long-term sequelae with the attendant challenges of managing them in our resource-poor setting and the need for behavioral changes and improved funding.

Pertinent literature on gynecological bacterial infections (GBIs) and sexually transmitted infections were retrieved following internet searches that used the databases of Google, Pubmed of the National Library of Medicine, WHO's Hinari, Wikipedia and some other websites.
Textbooks and selected references were also used in this review.

The following keywords were used for the searches: gynecological infections, vaginal infections and discharges, vaginal flora, sexually transmitted infections, pelvic inflammatory disease, syndromic management of STIs and challenges, psychosocial consequences and alternative medicine.

\section{Results of literature search}

A total of 5470 articles were obtained between 1947 and 2018. Out of which only 256 relevant articles on the topic were reviewed. However, 213 were dropped for having an incomplete submission. Forty-three (43) articles were fully accessed and referenced.

\section{Body/the review/discussion}

\section{Epidemiology}

The WHO (World Health Organization) estimated that about 499 million new cases of gynaecological bacterial infections occurred in the world in 2008 in men and women aged 15-49 years. ${ }^{22}$ In 1999, the WHO recorded the following regional incidences: North America 2-3\%, Western Europe 1-2\%, sub-Sahara Africa 11-35\% and Asia $9-17 \%{ }^{23,24}$ The true incidence in some countries like Nigeria is unknown as most published figures are hospital-based. Developing countries are believed to account for $80-90 \%$ of the global epidemiological burden of sexually transmitted infections (STIs). ${ }^{25}$

Most cases of gynecological bacterial infections (GBIs) are due to one or several of the under-listed organisms: Neisseria gonorrhea, Chlamydia trachomatis (serovars E, F, G), Bacteroides species, Streptococcus, Gardnerella vaginalis, Escherichia coli, Prevotella, Mycobacterium hominis, Ureaplasma urealyticum, Treponema pallidum, and Actinomycosis. ${ }^{20}$ Neisseria gonorrhea and Chlamydia trachomatis are the commonest causes of primary infections, while anaerobic organisms are responsible for secondary infections. ${ }^{14-17,26}$

\section{Pathology}

Bacterial infections in gynaecology can result in any of these: vulvitis, vaginitis, cervicitis, endometritis, salpingoophoritis, parametritis and the syndrome of pelvic inflammatory disease and this will constitute the bulk of our discussion here. ${ }^{27,28}$ Salpingoophoritis results in tubal damage, loss of ciliary action, tubal blockage, tubo-ovarian abscess, pelvic peritonitis, generalized peritonitis and pelvic abscess. Most cases result from Neisseria gonorrhea and chlamydial infections. The histological findings of lymphoid follicles and a mononuclear cell infiltrate are highly suggestive of chronic damage. 


\section{Clinical presentation}

Gynaecological bacterial infections may present with symptoms or remain asymptomatic. When present, symptoms may lack sensitivity and specificity or be transient and pass unnoticed. Mucopurulent vaginal discharge, lower abdominal pain and tenderness, adnexal tenderness, cervical motion tenderness, pyrexia > $380 \mathrm{C}$, dyspareunia, irregular and intermenstrual bleeding, symptoms of urinary tract infection, upper right quadrant pain and adnexal mass are common presentations.

\section{Laboratory evaluation}

Evaluation of patients may require the following laboratory investigations: a complete blood count which may show raised white blood cell count (WBC) and erythrocyte sedimentation rate, heavy growth of the offending organisms in high vaginal and endocervical swab microscopy, culture and sensitivity, presence of WBCs in saline preparations of vaginal secretions, $\mathrm{m} / \mathrm{c} / \mathrm{s}$ of endocervical swab, endometrial biopsy with histopathologic evidence of endometritis, mycobacterial studies on endometrial aspirates, C-reactive protein, CA125 , antichymotrypsin, orosomucoid and specific genital amylase. Ultrasonography especially transvaginal scan, CT scan and MRI scan facilitate the diagnosis.

The gold standard in diagnosis of pelvic inflammatory disease is laparoscopy which helps to exclude other surgical emergencies like ruptured ectopic pregnancy, acute appendicitis and endometritis; and allows the visualization of violin string adhesions which are classical. Abscesses can also be drained during laparoscopy.

Chlamydial antibodies estimation by enzyme linked immunosorbent assay (ELISA), direct fluorescent antibody, polymerase chain reaction(PCR), ligase chain reaction and transcription mediated nucleic acid amplification tests can also be done where the facilities exist. ${ }^{29}$

\section{Diagnosis}

While a thorough evaluation will lead to success in treatment and prompt recovery, it is pertinent to note that no one sign or symptom is pathognomonic and no single laboratory test is diagnostic. Criteria for diagnosis do exist for some of the gynaecological bacterial infections and for pelvic inflammatory infections, the criteria are classified into major and minor. The major criteria are abdominal tenderness, cervical motion tenderness and adnexal tenderness. The minor criteria include temperature (oral) $>380 \mathrm{C}, \mathrm{WBC}>10,000 / \mathrm{mm}^{3}$, pelvic or tubo-ovarian abscess, monoclonal smear positive for Chlamydia, positive Gram stain for gonococcus in endocervical smear, purulent material on culdocentesis and disseminated disease. The presence of all three major criteria and at least one of minor criteria are needed for a diagnosis of pelvic inflammatory disease to be made. The centre for disease control (CDC) recommends empirical treatment to be initiated in sexually active women if one or both of uterine or adnexal tenderness or cervical motion tenderness is present with no other causes.

\section{Complications}

\section{Physical consequences}

Bacterial infections in gynecology can be complicated by bacteremia and septicemia, Reiter's syndrome, 30 septic osteoarthritis, Fitz-Hugh-Curtis syndrome, aortic aneurysms and neurological complications. Chronic pelvic pain when present can be a cause of dyspareunia, menorrhagia, dysmenorrhea, marital disharmony, loss of man-hours, ectopic pregnancies and infertility are common complications of tubal damage from bacterial infections of the reproductive tract. ${ }^{31,32}$

Obstetric and perinatal complications can also arise from gynaecological bacterial infections and these include recurrent abortions, congenital abnormalities, neonatal infections, premature labour, premature rupture of membranes and increased perinatal mortality. ${ }^{11,33}$

\section{Psychosocial consequences}

These infections do not only affect the physical wellbeing of individuals but also can have profound psychosexual consequences on their lives. These range from increased concern and anxiety for their future fertility to disruption of relationships and guilt feelings, depression and isolation after a diagnosis. ${ }^{34-37}$ Though widespread screening for chlamydial infections has been advocated. ${ }^{38}$ Anxiety about male partner attitude and the stigma of sexually transmitted infections following a positive test may be too heavy a burden for women in unstable relationships to bear.

\section{Treatment}

The goal of management is aimed at treatment of current infection, prevention of long term sequelae, prevention of re-infection by contact tracing, institution of general preventive measures, mopping up toxic end-products of oxido-reduction by the organisms, reducing morbidity and health education. ${ }^{38}$

The modalities for treatment include medical, surgical and preventive therapies. The CDC 2015 guidelines for the treatment recommend the use of antibiotic combinations to cover susceptible bacteria making special provision for pregnancy and lactation, allergies and HIV infection. Some of the drugs are embryotoxic and excreted in milk. Well known drug examples include tetracyclines and quinolones. The choice of appropriate antibiotics should be influenced by;

- Robust evidence on local epidemiology of specific infections

- $\quad$ Cost effectiveness 
- Compliance and acceptability

- Severity of the disease

- Availability and

- $\quad$ Safety and toxicity profile.

Non-specific generalized treatment will include bed rest, analgesics, abstaining from unprotected sex while on treatment, nutritional as well as antioxidants supplements. Specific treatment commonly involves antibiotic combinations like quinolones, cephalosporins, clindamycin, gentamicin, doxycycline, azithromycin and imidazoles for anaerobic organisms. In some settings, delay in laboratory results prevents timely commencement of treatment. To circumvent this, a syndromic management strategy is resorted to.

\section{Syndromic management}

Syndromic management ensures that treatment can be initiated at any level of healthcare; is available, affordable and accessible to a greater majority of the population. ${ }^{39}$ It offers the opportunity for preventive and promotive measures; it is based on presumptive clinical diagnosis and is associated with identification of consistent group of symptoms and signs of infection and knowledge of common organisms involved.

Surgical treatment is less often used but may be indicated for drainage of abscess, culdocentesis, unilateral salpingectomy and hysterectomy. Small abscesses in the pouch of Douglas can be drained by ultrasound-guided aspiration. Laparoscopy or laparotomy may be used for drainage of abscess diagnosed on ultrasound scanning and that fails to resolve with antibiotics. Salpingoophorectomy is used for treating a large tuboovarian abscess depending on patient's age and reproductive history. Surgery should be avoided where pelvic actinomycosis is suspected.

\section{Preventive measures}

Preventive measures are imperative to stem the tide of gynaecological bacterial infections. Primary preventive measures include sex education, female education and empowerment as well as improved standard of living. Secondary measures such as aseptic deliveries and surgical procedures, antenatal screening for infections and contact tracing are important. Prompt diagnosis and treatment and management of complications are good tertiary preventive measures

\section{Challenges of management of $G B I$ in resource- limited settings}

Managing gynaecological bacterial infections in a resource-limited setting is fraught with a lot of challenges. Low socioeconomic status limits access to affordable health care.
Certainly, laboratory diagnosis is the most accurate method of diagnosis but is mostly not feasible as it is expensive, time consuming, requires sophisticated equipment and qualified personnel. Syndromic diagnosis while attempting to fill the gap relies on subjective judgement, cannot detect asymptomatic infections, and may lead to overdiagnosis/overtreatment with potential drug resistance..$^{40-42}$

Unhealthy cultural practices deeply rooted in traditions constitute a formidable obstacle to managing these conditions. Examples like wife inheritance and wife sharing as well as polygamy and promiscuity deserve mentioning. These enhance spread of infections while making control and total cure practically difficult.

The absence of screening for infections at adolescent clinics and STD clinics, antenatal clinics and correctional facilities also hamper management. Indeed, the diagnosis and treatment of gonococcal and chlamydial infections in pregnant women remain the best method for preventing neonatal gonococcal and chlamydial infections.43 Currently many antenatal clinics do not screen for Chlamydia. Regular screening of commercial sex workers will help in curbing the spread of these infections.

Poor and inconsistent use of barrier method of contraception is still prevalent in our settings. The unavailability and high cost of genuine drugs has led to widespread use of substandard and counterfeit drugs with the consequences of resistant infections that run a chronic course and a gamut of complications.

Sadly, the health budgets of many countries in subSaharan Africa remain in the single digit range. Funds are scarce, health workers have unrealized expectations as their morale dip low, hospital clinics are poorly patronized, and the sick receive suboptimal care. Surely the challenges are enormous and daunting..

\section{CONCLUSION}

It is a well-known fact that bacterial infections of the female genital tract are common and peculiar socioeconomic factors in our environment contribute immensely to this scourge. Untreated and poorly treated cases have far-reaching implications that are disturbing and debilitating. The economic and health burden can be substantial. The diagnostic tools that are available lack sensitivity and specificity. Prompt diagnosis and aggressive approach to treatment as well as health education are extremely beneficial. Early sex education, delaying age of sexual debut and total abstinence till marriage are commendable approaches. Indeed, the role of family and parental support in helping their teenage children to safely navigate sexual relationships cannot be over-emphasized. One study found prevalence rate as high as $37.7 \%$ among sexually experienced teenagers. Health strategies aimed at prevention will lead to a reduction in the risk and progression of physical, social 
and psychological burden associated with these infections. Female education and economic empowerment subsidized and affordable health care will encourage people to seek treatment early and avert complications. A national screening policy at community level will help in early identification, partner tracing and treatment. This should be an integral part of policy and decision making.

\section{ACKNOWLEDGMENTS}

Authors would like to thank most sincerely acknowledge residents and the secretarial staff of the department of Obstetrics and Gynaecology, University of Nigeria Teaching Hospital, Ituku-Ozalla, Enugu for their tireless effort in making this work a success. May God bless them all.

\section{Funding: No funding sources}

Conflict of interest: None declared

Ethical approval: Not required

\section{REFERENCES}

1. Gorbach SL, Menda KB, Thadepalli H, Keith I. Anaerobic flora of the cervix of healthy women. Am J Obstet Gynecol. 1973;117:1053-5.

2. Yamamoto T, Zhou X, Williams CJ, Hochwalt A, Forney U. Bacterial populations in the vaginas of healthy adolescent women. J Pediatric Adolesc Gynecol. 2009;22:11-8.

3. Zhou X, Bent SJ, Schneider MG, Davies CC, Islam MR, Forney U. Characteristics of vaginal microbial communities in adult healthy women using cultivation independent methods. Microbiol. 2004; 150:2565-73.

4. Shi Y, Chen L, Tong J, Xu C. Preliminary characterization of vaginal microbiota in healthy Chinese women using cultivation independent methods. J Obstet Gynecol Res. 2009;35:525-32.

5. Keane FE, Ison CA, Taylor-Robinson DA. A longitudinal study of the vaginal flora over a menstrual cycle. Int J STD AIDS. 1997;8:489.

6. Wertz J, Isaacs Cosgrave N, Holzman C, Marsh TL. Temporal shifts in microbial communities in Nonpregnant African-American women with and without bacterial vaginosis. Inter Persp Infect Dis. 2008; 18:123-5.

7. Srinivasan S, Liu C, Mitchell CM, Fiedler TL, Thomas KK, Agnew KJ, et al. Temporal variability of human vaginal bacteria and relationship with bacterial vaginosis. Plos ONE. 2010;5:e10197.

8. Lamont $\mathrm{R}$, Sobel J, Akins $\mathrm{R}$, Hassan $\mathrm{S}$, Chaiworapongsa T, Kusanovic J, et al. The vaginal microbiome: new information about genital tract flora using molecular based techniques. BJOG. 2011;118:533-49.

9. Johnson SR, Petzold CR, Galask RP. Qualitative and quantitative changes of the vaginal microbial flora during the menstrual cycle. Am J Reprod Immunol Microbiol. 1985;9:1-5.

10. Witkin SS, Linhares IM, Giraldo P. Bacterial flora of the female genital tract; function and immune regulation. Best Pract Res Clin Obstet Gynecol. 2007;21:347-54

11. Digma F. HIV-infected women of Burkina Faso: a "reservoir" of mycoplasma infection. J Infect Dev Ctries. 2011;3(5):176-81.

12. Martino J, Vermund SH. Vaginal douching: evidence for risks and benefits to women's health. Epidemiol Rev. 2002;24:109-24.

13. Currie MJ, Bowden FJ. The importance of chlamydial infection in obstetrics and gynecology: An update. Aus NZ J Obstet Gynaecol. 2007;47:2-8.

14. Lauman EO. Racial/Ethnic group differences in the prevalence of sexually transmitted diseases in the United States: a network explanation. Sex Transm Dis. 1999;26(5):250-61.

15. Centre for diseases control factsheet: pelvic inflammatory disease, 2011. Available at: https://www.cdc.gov/std/pid/stdfact-pid/htm. Accessed on $11^{\text {th }}$ December 2015.

16. Einwater LA, Ritchie JM, Ault KA, Smith M. Gonorrhea and chlamydial infection among women visiting Family Planning Clinics: Racial variation, Prevalence and Predictors. Persp Sex Reprod Health. 2005;37(3):135-40.

17. Johnson LF, Coetzee DJ, Dorrington RE. Sentinel surveillance of sexually transmitted infections in South Africa: a review. Sex Transm Infect. 2005;81:287-93.

18. Hogben M, Leichliter JS. Social determinants and sexually transmitted disease disparities. Sex Transm Dis. 2008;35(12 suppl):S13-18.

19. Aboyeji AP, Nwabuisi P. Prevalence of sexually transmitted diseases among pregnant women in Ilorin Nigeria. J Obs Gynecol. 2003;23(6):637-9.

20. Chinsembu KC. Sexually transmitted infections in adolescents. The Open Infect Dis J. 2009;3:107-17.

21. Ebisi NT. The impact of culture on the transmission of infectious diseases in Nigeria; The case of Awka south, Anambra State. Afr J Social Sci. 2012;2(4):173-90.

22. UNAIDS WORLD AIDS Report, 2011. Available at: https://www.unaids.org/en/resources/documents/201 1/20111121_JC2216_WorldAIDSday_report_2011. Accessed on $21^{\text {st }}$ November 2011.

23. The European health report 2002 - WHO/Europe World Health Organization. Available at: www.euro.who.int/_data/assets/pdf_file/0007/98296/ E76907.pdf. Accessed 15 ${ }^{\text {th }}$ August 2002.

24. WHO Global Strategy for Containment of Antimicrobial Resistance. Available at: www.who,int/csr/resources/publications/drugresist/E Global_Strat.pdf. Accessed on $11^{\text {th }}$ January 2001.

25. Miller WC. Prevalence of chlamydial and gonococcal infection among young adults in the US. JAMA. 2004;291(18):2229-36. 
26. Barret S, Taylor C. A review on pelvic inflammatory disease. Int J STD AIDS. 2005;16:715-20.

27. Crossman SH. The challenge of pelvic Inflammatory disease. Am Fam Physician. 2006;73:859-64.

28. Van Der Pol B, Kraft CS, Williams JA. Use of an adaptation of a commercially available PCR assay aimed at diagnosis of Chlamydia and gonorrhea to detect Trichomonas Vaginalis in Urogenital Specimens. J Clin Microbiol. 2006;44(2):366-73.

29. Arya OP. Chlamydia, other non-gonococcal and nonspecific infections and Reiter's syndrome. Liverpool UK: Department of Medical Microbiology and Genitourinary Medicine, University of Liverpool; 1998.

30. Blandford JM, Gift TI. Productivity losses attributable to untreated chlamydial infection and associated pelvic inflammatory disease in reproductive-age women. Sex Tansm Dis. 2006;33(10 suppl):S117-S121.

31. Frederick R, Je Covsek MD. Severe pelvic infection and infertility. Women's diagnostic Cyber. 2000.

32. French JI, McGregor JA, Parker R. Readily Treatable Reproductive tract infections preterm birth among black women. Am J Obstet Gynecol. 2006;194:1717- 26.

33. Jonathan DC, Stewart P. Pelvic Infections in: Dewhurst's Textbook of Obstetrics and Gynaecology $7^{\text {th }}$ edition. Keith Edmonds. Blackwell Publishing 9600 Garsington Road Oxford. 2007.

34. Bird FM, Rosenthal S. Psychological sequelae of sexually transmitted diseases in adolescents. Obstet Gynecol Clin North Am. 1992;19:209-18.

35. Duncan B, Hart G, Scoular A, Bigrigg A. Qualitative analysis of psychosocial impact of diagnosis of Chlamydia trachomatis: implications for screening. BMJ. 2001;322:195.

36. Gottlieb SL, Stoner BP, Zaidi AA, Buckel C, Tran M, Leichliter JS, et al. A prospective study of the psychosocial impact of a positive Chlamydial Trachomatis Laboratory test. Sex Transm Dis. 2011;38(11):1004-11.

37. Peterman TA, Tian LH, Metcalf CA. High incidence of new sexually transmitted infections in the year following a sexually transmitted infection: A case for screening. Ann Intern Med. 2006;145:564-72.

38. Marianne SD, Donna G. The centre for disease control and prevention guidelines for the treatment of sexually transmitted diseases: implication for Women's health care. J Midwifery Women Health. 2003.

39. Training module on syndromic management of sexually transmitted infections, 2007. Available at: https://www.who.int/reproductivehealth/publications/ rtis/9789241593407/en/. Accessed on 2007.

40. Ghebremichael M. Syndromic versus laboratory diagnosis of sexually transmitted infections in resourcelimited setting. Int Sch Res Notices. AIDS. 2014.

41. Bosu WK. Syndromic management of sexually transmitted diseases: is it rational or scientific? Trop Med Int Health. 1999;4(22):114 -9.

42. Lush L, Walt G, Ogden J. Transferring Policies for treating sexually transmitted infections: what's wrong with global guidelines? Health Policy Planning. 2003;18(1):18-30.

43. Workowski KA, Berman SM. Sexually transmitted diseases treatment guidelines. CID. 2011:53(3):1-12.

Cite this article as: Adiri CO, Nwagha UI, Okeke TC, Izuka EO. Gynaecological bacterial infections: the physical and psychosocial consequences and challenges of management in resource-limited settings. Int J Reprod Contracept Obstet Gynecol 2019;8:4114-9. 